\title{
Neuroprotective effect of Clerodendron glandulosum against acute transient ischemia reperfusion cerebral injury in rats.
}

\author{
Saritha Surapaneni, Prakash T*, Asif Ansari, Divakar Goli \\ Department of Pharmacology, Acharya B.M. Reddy College of Pharmacy, Bangalore-560 107, Karnataka, India
}

\begin{abstract}
Cerebral ischemia may be due to primary thrombosis in carotid artery. This results in cerebral hypoxia and thus leading to cerebral infarction/ischemic stroke. The effect of CGE (C. glandulosum extract) on antioxidant status in $I / R$ (ischemia-reperfusion) injury in the rat forebrain have been investigated. Further, its effect was assessed on behavioural parameters, infract size and histopathological parameters. Bilateral carotid artery occlusion followed by reperfusion produced significant cerebral infarction and impaired short term memory, motor co-ordination and lateral push response CGE markedly attenuated $I / R$ induced cerebral injury in terms of decreased infarct, size. The result suggests that the use of CGE protect ischemia reperfusion induced cerebral injury with comparable potency.
\end{abstract}

Keywords: Neuroprotective activity, Cerebral ischemia, Infarct size, Oxidative stress, C. glandulosum.

\section{Introduction}

Cerebral ischemia is a condition in which there is insufficient blood flow to the brain to meet metabolic demands. This leads to poor oxygen supply or cerebral hypoxia and thus leading to the death of brain tissues or cerebral infraction/ischemia stroke. It has been third most common cause of death in developed countries, Stroke can affect walking, talking, speech, vision, spatial awareness, swallowing, bladder control, bowel control and balance co-ordination. Free radical formation has been proved during cerebral ischemia. Risk factors for stroke include advanced age, hypertension, transient ischemic attack, diabetes; high cholesterol, cigarette smoking and atrial fibrillation. Among stroke patients, $80 \%$ suffer from cerebral infraction and $20 \%$ from cerebral haemorrhage $[1,2]$. Several components of reactive oxygen species (ROS) (superoxide, hydroxyl radical, hydrogen peroxide and peroxynitrite radical) that are generated after ischemia - reperfusion injury play an important role in neuronal loss after cerebral ischemia [3]. In reperfusion injury arrivals of oxygen to the ischemia area following restoration of blood flow instead of alleviating ischemic state worsens damage. Xanthine oxidase (XO) is major factor in generation of superoxide radical has been consider to play an important role in genesis of tissue injury due to ischemia and reperfusion. There is evidence that XO levels are elevated during ischemia. XO is the first known $\mathrm{O}_{2}$ radical source. During ischemia, adenosine triphosphate is degraded to hypoxanthine and xanthine dehydrogenase is converted to XO. During reperfusion, XO catalyses the conversion of hypoxanthine to uric acid with release of $\mathrm{O}_{2}$ radical [3]. Nitric oxide synthase (iNOS) is up regulated after reperfusion injury. This results in excessive nitric oxide (NO) production. However some reports suggested that NO inhibits XO activity. Many antioxidants are reported to reduced reactive oxygen species-mediated reaction and protect neurons from ischemia-reperfusion induced neural loss in animal models of cerebral ischemia [4-6]. Cerebral ischemia leads to inflammatory cells which releases inflammatory cytokines and leads to accumulation of adhesion molecules mainly results in breakdown of blood brain barriers (BBB) Hence in this study we wanted to understand the role of XO inhibition, NO inhibition by C. glandulosum [7.]

In 2011 it is reported that $C$. glandulosum leaves extract exhibits potent hepatoprotective activity against $\mathrm{CCl}_{4}$-induced hepatic damage but does not exhibit any toxic manifestations and changes in plasma marker enzymes, hepatic lipid peroxidation, enzymatic and non-enzymatic antioxidants total protein levels of superoxide dismutase and catalase are estimated. Traditionally, people across Manipur consume decoction of C. glandulosum leaves for treating diabetes, obesity and hypertension and antioxidant property [8]. Therefore, the present study has been designed to investigate the effect C. glandulosum hydroalcoholic leaf extraction ischemicreperfusion induced cerebral injury in rats.

\section{Materials and Methods}

\section{Plants}

C. glandulosum plant leaves were procured from Manipur India. The plant was authenticated by Dr. T.H Brojendra Singh, Institute of Bio Tech Hub Centre, Takyalapat, Imphal and Manipur (1BTH-OC-01-2013/6). The voucher specimen of the plant was deposited in the department. All other chemicals and reagents used were of analytical grade and procured from approved vendors.

\section{Preparation of extract}

The leaves of $C$. glandulosum were shade dried. Dried leaves were then powdered and passed through sieve no: 44. Fine powder was collected; $100 \mathrm{~g}$ of fine powder was packed and extracted by using ethanol:water $(70: 30)$ at $65^{\circ} \mathrm{C}$ to $70^{\circ} \mathrm{C}$ for 24 $\mathrm{h}$ in soxhlet apparatus. After extraction the solvent was removed by using vacuums evaporator. Dried extract was stored in bottle wrapped with aluminium foil at $2^{\circ} \mathrm{C}$ to $8^{\circ} \mathrm{C}$. The chemical constituents of the hydroalcoholic extract of C. glandulosum were identified by qualitative analysis [9]. 


\section{Animals}

Male albino Wistar rats (150 g to $200 \mathrm{~g})$ were obtained from Bioneeds, Bangalore and Karnataka. Animals were caged in fully ventilated room. Animals were maintained in 12:12 h light and dark cycle and were housed at temperature of $25^{\circ} \mathrm{C} \pm 2{ }^{\circ} \mathrm{C}$. They had free access to a standard chow diet and water ad libitum. Study protocol was approved by IAEC (protocol number-IAEC/ ABMRCP/2012-13/26). All the experiments were performed in accordance with the guidelines of CPCSEA.

\section{Preliminary acute toxicity test}

Healthy adult male albino mice ( $20 \mathrm{~g}$ to $25 \mathrm{~g}$ ) were subjected to acute toxicity studies as per guidelines (AOT 425) suggested by the Organization for Economic Co-operation and Development (OECD-2000). Animals were divided into two groups $(n=5)$. The animals where fasted for $4 \mathrm{~h}$ and with free access to water. The $C$. glandulosum extract was administered orally in doses of $2500 \mathrm{mg} / \mathrm{kg}$ and $5000 \mathrm{mg} / \mathrm{kg}$ to different groups of mice and observed over 14 days for mortality and physical/behavioural changes [10].

\section{Experimental design}

All the experiment was carried out in accordance with guidelines of committee for purpose of control and supervision of experiments on animals (CPCSEA) and the institutional animal ethics committee (IAEC) the approval no. was (protocol number-IAEC/ABMRCP/2012-13/26). Sufficient measures were adopted to minimize pain and discomfort with animal experimental procedures. The bilateral common carotid arteries were subsequently isolated and $30 \mathrm{~min}$ of ischemia was given to the rat by blocking the left internal branch of the common carotid artery was occluded with micro vascular clip. After the ischemic period, the neck muscle was stitched and ointment applied each rat. The test extract was administered to the respective group of rats described below for a period of 8 days. Rats were anesthetized and divided in to five groups of eight animals each. Sham group (Group I), rats were subjected to surgical procedure and a thread was passed below both carotid arteries but the arteries were not occluded. After $30 \mathrm{~min}$, thread was removed and the animal was sutured back and allowed to recover for 4 h. Control ischemia/reperfusion (I/R) group (Group II), rats were subjected to $30 \mathrm{~min}$ global cerebral ischemia followed by reperfusion for $4 \mathrm{~h}$. Group III and Group IV was treated with CGE (C. glandulosum extract) at dose of $200 \mathrm{mg} / \mathrm{kg}$ and 400 $\mathrm{mg} / \mathrm{kg}$ body weight orally and rats were subjected to global cerebral ischemia on $8^{\text {th }}$ day. Group $\mathrm{V}$ rats were treated with standard drug (Quercetin $10 \mathrm{mg} / \mathrm{kg}$, p.o) and rats are subjected to global cerebral ischemia on $8^{\text {th }}$ day employed for the study.

\section{Neurobehavioral test}

Neurodeficit score: The neurological state of the animals was evaluated using four categories of neurological findings were observed and noted $0=$ no observed neurological deficit; $1=$ contralateral forelimb flexion with wrist flexion and shoulder adduction; $2=$ reduced resistance to lateral push and $3=$ circling movements towards the ipsilateral side [11].

\section{Rota rod test}

Sensorimotor performance was evaluated using a rota rod test. All animals were tested for their ability to remain on the rotating bar at a speed of 20 revolutions/min (rpm) on a Rota rod apparatus (Inco). Each animal was trained for a minimum of three trials. After 8 post ischemic days, the animals were tested for motor impairment after administration of test drugs. Latency to fall off from the rotating rod was noted for each trial with a 5 min maximum to termination of the trials.

\section{Hanging wire}

The experimental animals were suspended by its forelimbs on a wire stretched between two posts, $45 \mathrm{~cm}$ above a foam sheet. The time in seconds (s), until the animal fell down, was recorded. 2 min of cut off time was designated. This task was used as a measure of grasping ability and forelimb strength.

\section{Beam walk test}

Beam walk test was employed to evaluate fore and hind limbs motor coordination. Each animal was individually placed on a beam walk apparatus (Inco) made up of a wooden bar $60 \mathrm{~cm}$ long and $1.5 \mathrm{~cm}$ wide, height $50 \mathrm{~cm}$. The motor performance of rat scored on a scale ranging from 0 to 4 . This is a special test for animals subjected to cerebral ischemia and reperfusion. For motor incoordination, number of foot slip; Number of falls; Distance travelled along beam was studied [12].

\section{Open field test}

The locomotor activity was evaluated in an open field paradigm. The apparatus consisted of a wooden box $(60 \times 60 \times 30 \mathrm{~cm})$. The floor of the box was divided into 16 squares $(15 \times 15 \mathrm{~cm})$. The apparatus was illuminated with a 40-W lamp suspended $100 \mathrm{~cm}$ above. Each animal was placed at one corner of the apparatus and for the next $5 \mathrm{~min}$ it was observed for the ambulation (number of squares crossed), total period of immobility (in seconds), number of rearing's, grooming, faecal pellets was observed [13].

\section{Elevated plus maze}

The elevated plus maze apparatus consists of a central platform connected to two open arms and two enclosed arms. The maze is elevated to a height of $50 \mathrm{~cm}$ from the floor. During training trials the animal was placed at the end of an open arm, facing away from the central platform of the maze. The time taken by the animal to move from open arm and cross the line marked in enclosed arm with all four paws was recorded as transfer latency (TL) time. In case the rats did not enter the enclosed arm within $90 \mathrm{~s}$, it was gently pushed into the enclosed arm and a TL of $90 \mathrm{~s}$ was assigned to it. The animal was allowed to remain in the maze for the duration of $10 \mathrm{~s}$. The TL measured on the plus maze on the 1 day serves as an index of acquisition, whereas the TL measured after $24 \mathrm{~h}$ of acquisition trial was taken as an index of retrieval [14].

\section{Morris water maze test}

The test for learning and memory on day $8^{\text {th }}$ after surgery, spatial learning and memory was tested in water maze. The maze consists of a black circular pool (diameter $2.14 \mathrm{~m}$, height $80 \mathrm{~cm}$ ) filled to a depth of $44 \mathrm{~cm}$ with water $\left(25^{\circ} \mathrm{C}\right)$. The rats received habituation (exposure in water maze for $1 \mathrm{~min}$ ) in which there is no platform present. Then, on day $8^{\text {th }}$, a circular platform $(9$ $\mathrm{cm}$ in diameter) was kept hidden $2 \mathrm{~cm}$ below water level in the center of one of the quadrants. The platform remains in the same position during training days [15]. 


\section{Preparation of brain homogenate}

After decapitation, ischemia/reperfusion groups the brain was removed and washed in ice chilled $0.9 \%$ saline, and was kept on ice and subsequently blotted on filter paper, then weighed and homogenized in cold phosphate buffer $(0.1 \mathrm{M}, \mathrm{pH} 7.4)$ to make a $10 \% \mathrm{w} / \mathrm{v}$ homogenate using a homogenizer. The homogenate was centrifuged at $10,000 \mathrm{rpm}$ for $20 \mathrm{~min}$ at $4^{\circ} \mathrm{C}$ and supernatant was kept in deep refrigerator at $-80^{\circ} \mathrm{C}$ for analyzing biochemical estimations ( SOD, CAT, MDA, MPO) [16].

\section{Infarct size measurement}

The brain was removed and frozen at $-4^{\circ} \mathrm{C}$ for $5 \mathrm{~min}$. Coronal slices were made at $1 \mathrm{~mm}$ to $2 \mathrm{~mm}$ and sections were immersed in $1 \%$ of 2,3,5-triphenyltetrazolium chloride (TTC) at $37^{\circ} \mathrm{C}$ for $20 \mathrm{~min}$. TTC is converted to red formazone pigment by NAD and dehydrogenase present in living cells. Hence, viable cells were stained deep red. The infarcted cells have lost the enzymes and thus remained unstained. Whole brain slices were weighed. Infarcted unstained part was dissected out weighted and expressed as $\%$ of total weight of brain [17].

\section{Histopathological examination}

At the end of experimental procedures, rats were sacrificed and the brains were dissected out. The brains were transferred to $10 \%$ formalin. Sections $(<5 \mu \mathrm{m}$ thick) of the frontal forebrain were prepared and stained by hematoxylin and eosin for microscopical examination [15].

\section{Statistical analysis}

The results were expressed as Mean \pm SD. SOD, CAT, MDA, MPO and percentage of infraction were determined by factorial One-way ANOVA. Individual group was compared against control using Dunnet's test. Values ranging between $\mathrm{P}<0.05$ and $\mathrm{P}<0.001$ were considered statistically significant. Statistical analysis was performed using Graph Pad Prism software (Version 5.01).

\section{Results}

\section{Effect of CGE on behavioral parameters}

Effect of CGE on Neurodeficit score, rota rod test, hanging wire test, beam walk test, Open field test, Elevated plus maze test, Morris water maze test results are represented in Tables 1-3. The rat model of ischemia was established by temporary blocking of the internal carotid artery for $30 \mathrm{~min}$ of ischemia followed by reperfusion and it leads to sudden loss of vision, balance, coordination and memory. The neurological status of the rat was assessed by behavioural test. Neurodeficit scoring, pole fall and hanging wire results showed impairment in neurobehavioral scale in Group-2 ischemic rats. The neuro behavioral parameters neurological deficit score, grasping ability, forelimb strength, and motor function, were significantly improved in treated groups of CGE. Pre-treatment with CGE $200 \mathrm{mg} / \mathrm{kg}$ significantly in $(P<0.01)$ increase behavioural test compared to I/R.

Table 1. Effect C. glandulosum on neurobehavioral tests in ischemia-reperfusion injury in rats.

\begin{tabular}{|c|c|c|c|c|c|}
\hline \multirow{2}{*}{ Treatment Groups } & Dose & \multicolumn{2}{|c|}{$\begin{array}{c}\text { Neurodeficit Rota rod } \\
\text { (Mean fall time in s) }\end{array}$} & $\begin{array}{c}\text { Beam walk test (s) } \\
\text { (Mean fall time in s) }\end{array}$ \\
\cline { 2 - 6 } & Normal saline & Mean score & $4.128 \pm 0.621$ & $64.3 \pm 1.978$ \\
\hline Sham & Normal saline & 0 & $2.131 \pm 0.234$ & $38.9 \pm 1.132$ \\
\hline I/R & 200 & 1.8 & $3.325 \pm 0.242$ & $52.06 \pm 1.241$ \\
\hline C.G & 400 & 0.8 & $3.281 \pm 0.272$ & $49.4 \pm 1.288$ \\
\hline Quercetin & 10 & 1.1 & $3.091 \pm 0.215$ & $45.6 \pm 1.806$ \\
\hline
\end{tabular}

Table 2. Effect of C. glandulosum on open field test in ischemia-reperfusion injury in rats.

\begin{tabular}{|c|c|c|c|c|c|}
\hline $\begin{array}{c}\text { Treatment } \\
\text { Groups }\end{array}$ & $\begin{array}{c}\text { Dose } \\
\text { mg/kg,p.o. }\end{array}$ & $\begin{array}{c}\text { Ambulations } \\
\text { (Number) }\end{array}$ & $\begin{array}{c}\text { Immobility } \\
\text { (Seconds, s) }\end{array}$ & $\begin{array}{c}\text { Grooming } \\
\text { (Number) }\end{array}$ & $\begin{array}{c}\text { Rearing } \\
\text { (Number) }\end{array}$ \\
\hline Sham & Normal saline & $48.80 \pm 4.85$ & $164.70 \pm 23.67$ & $4.80 \pm 0.98$ & $6.30 \pm 0.83$ \\
\hline I/R & Normal saline & $18.90 \pm 1.98$ & $129.09 \pm 23.87$ & $3.56 \pm 0.43$ & $2.60 \pm 0.87$ \\
\hline C.G & 200 & $22.09 \pm 4.09$ ns & $154.00 \pm 18.09^{* *}$ & $4.70 \pm 0.76$ \\
\hline C.G & 400 & $34.98 \pm 3.98 * *$ & $123.25 \pm 17.76^{* *}$ & $5.90 \pm 1.23$ & $5.69 \pm 0.87$ \\
\hline Quercetin & 10 & $23.00 \pm 5.45$ & $145.00 \pm 10.65$ & $2.50 \pm 0.76^{* * *}$ & $2.00 \pm 1.07^{* *}$ \\
\hline
\end{tabular}

The values are expressed as Mean \pm SD. Data was analyzed by One-Way Analysis of Variance (ANOVA) followed by Dunnett's test. ${ }^{*} p<0.05,{ }^{* *} p<0.01,{ }^{* * *} p<0.001$ as compared to I/R Vehicle control, ns- non-significant, $p<0.05$ as compared to I/R Vehicle control

Table 3. Effect of C. glandulosum on elevated plus maze test ischemia-reperfusion injury in rats.

\begin{tabular}{|c|c|c|c|c|c|c|c|}
\hline \multirow{2}{*}{ Treatment } & \multirow{2}{*}{ Dose mg/kg,p.o. } & \multicolumn{2}{|c|}{ Time Spent In Seconds } & \multicolumn{2}{|c|}{ No. of Entries } & \multirow{2}{*}{\begin{tabular}{|c|} 
Ratio of \\
$\begin{array}{c}\text { Time Spent (OA } \\
\text { CA) }\end{array}$
\end{tabular}} & \multirow{2}{*}{$\begin{array}{c}\text { Ratio Of No. Of } \\
\text { Entries }\end{array}$} \\
\hline & & $\begin{array}{c}\text { CA (Closed } \\
\text { arm) }\end{array}$ & OA (Open arm) & CA & OA & & \\
\hline Sham & Normal saline & $187.4 \pm 2.1$ & $45.2 \pm 87.2$ & $3 \pm 0.57$ & $2 \pm 0.25$ & $0.436 \pm 0.24$ & $0.4 \pm 0.87$ \\
\hline I/R & Normal saline & $145.2 \pm 7.34$ & $3.3 \pm 43.3$ & $1.87 \pm 0.9$ & $1.5 \pm 0.9$ & $0.17 \pm 0.71$ & $0.941 \pm 0.64$ \\
\hline C.G & 200 & $205.34 \pm 21.8$ & $5.15 \pm 0.23$ & $3.01 \pm 0.9$ & $1.87 \pm 0.23$ & $0.143 \pm 0.98$ & $0.38 \pm 0.26$ \\
\hline C.G & 400 & $183 \pm 54.2$ & $18.13 \pm 0.86^{*}$ & $3.75 \pm 0.5^{\star *}$ & $2.25 \pm 0.95^{\star *}$ & $0.125 \pm 0.09^{\star *}$ & $0.583 \pm 0.20^{* *}$ \\
\hline Quercetin & 10 & $\begin{array}{c}283.25 \pm 24.06 \\
n s\end{array}$ & $28.25 \pm 12.90$ * & $2.65 \pm 0.95^{\star *}$ & $1.75 \pm 0.50^{\star *}$ & $0.093 \pm 0.05^{\star *}$ & $0.512 \pm 0.23^{\star *}$ \\
\hline
\end{tabular}

All values are expressed as Mean $\pm \mathrm{SD}$. Data was analyzed by One-Way Analysis of Variance (ANOVA) followed by Dunnett's test. * $p<0.05$ ** $p<0.01$ as compared to I/R Vehicle control; ns- non-significant 
Citation: Surapaneni S, Prakash T, Ansari A, et al. Neuroprotective effect of Clerodendron glandulosum against acute transient ischemia reperfusion cerebral injury in rats. J Neurol Neurorehabil Res. 2017;2(1):14-20.

\section{Effect of CGE on biochemical enzymes}

The biochemical results are showed in Figure 1. The results showed that the reperfusion significantly decreased antioxidant levels (SOD and CAT) and increased the MDA and MPO levels in the injured brain tissue of rats as compared with the sham control group. However, the treatment of rats with CGE (200 and $400 \mathrm{mg} / \mathrm{kg}$ ) was markedly increased SOD and CAT, activity. In contrast, MDA and MPO content in the injured brain tissue of rats decreased significantly $(P<0.01)$ in CGE treated group compared to ischemic control group.

\section{Effect of CGE on infarct size in rat brain tissue}

Global cerebral ischemia followed by reperfusion produced significant increase in cerebral infarction measured by volume and weight method in reperfusion animals. Treatment of CGE marked by attenuated decrease in cerebral infract size in a dose dependent manner as compared control group and significant reduction in $(P<0.01)$ in treatment group (Figure 2). The percentage of brain infarction was recorded in control and treated group was expressed in Figure 3.

\section{Effect of CGE on histopathological studies}

Histopathological studies of the brain of I/R groups showed some pyramidal cells and neuroglial cells shown degenerative changes (necrosis) few of the blood vessels show fibrinoid necrosis with features of vasculitis as shown. Extract treated groups was showed changes in blood vessels and change in necrosis decrease in congested blood vessels and gliosis, no odema was observed in reperfusion animals and it is represented in Figure 4.

\section{Discussion}

Global cerebral ischemia and reperfusion model employed in the present study is reported to simulate the clinical situation of cerebral ischaemia [16]. Prolonged global cerebral ischemia results in neuronal death irrespective of post ischemic reperfusion [17]. Cerebral ischemia has been reported to impair short-term memory because hippocampal neurons are susceptible to the deleterious effects of ischemia and reperfusion [18]. The activities of extract appeared to work by restoring the altered antioxidants enzymes as well as decreasing the lipid peroxidation in brain regions induced by ischemia reperfusion. There is considerable evidence which supports the role of ROS in the pathogenesis of $\mathrm{I} / \mathrm{R}$ induced oxidative stress in brain $[19,20]$. Superoxide dismutase, Catalase act together against reactive oxygen species and free radical damage. Superoxide dismutase (SOD) is a ubiquitous enzyme with an essential function of protection of aerobic cells against oxidative stress. It is primarily a mitochondrial enzyme usually found in the plasma membrane [21]. Superoxide dismutase and Catalase are mutually supportive members of defence against reactive oxygen species which have been found to be decreased during ischemia reperfusion injury [22]. In the present study, CGE treatment significantly restored antioxidant enzyme (SOD and Catalase) oxidative defence. The ROS of potential importance in cerebral ischemia include superoxide and hydroxyl radicals and their formation was indicated and confirmed by an increase in hydroxylated salicylate in post ischemic insults. ROS produces malondialdehyde (MDA), an MDA reacts with TBA and produces TBARS, producing superoxide and $\mathrm{H}_{2} \mathrm{O}_{2}$ in the
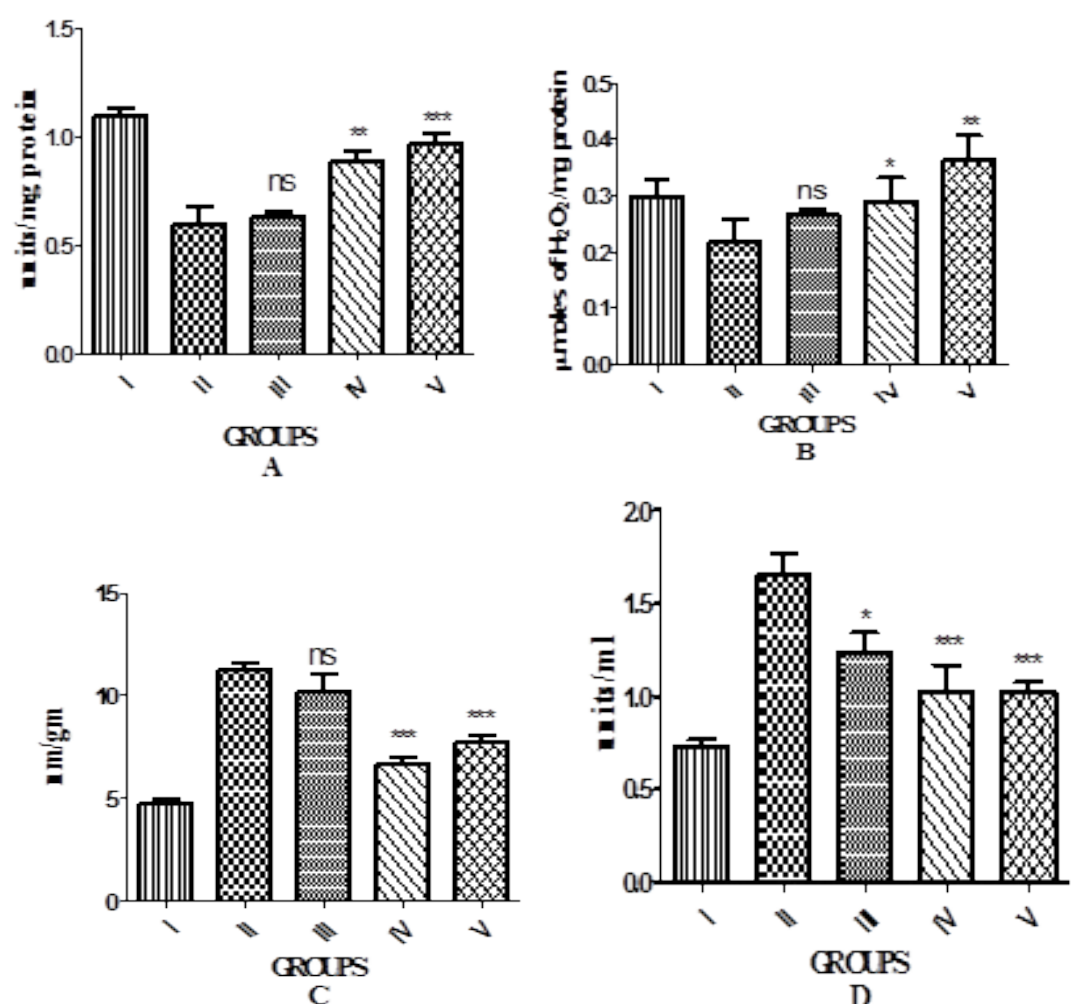

Figure 1. Effect of hydroalcoholic extract of C. glandulosum on SOD (Figure 1A), CAT (Figure 1B), MDA (Figure 1C) and MPO (Figure 1D) of the rat brain subjected to reperfusion in BCCAO occlusion. I: Sham control, no occlusion (normal saline, $1 \mathrm{ml} / \mathrm{kg}$, p.o.), II: Reperfusion in BCCAO ischemic control (normal saline, $1 \mathrm{ml} / \mathrm{kg}$, p.o.), III: Reperfusion in BCCAO + C. glandulosum (200 mg/kg, p.o.), IV: Reperfusion in BCCAO + C. glandulosum (400 mg/kg, p.o.), V: Reperfusion in BCCAO + Quercetin (10 mg/kg, p.o.). 


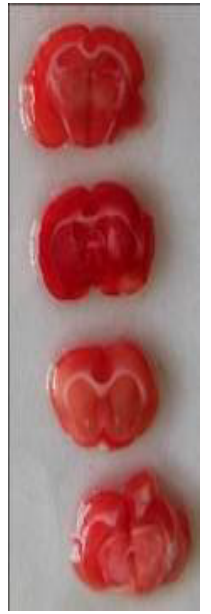

$\boldsymbol{A}$

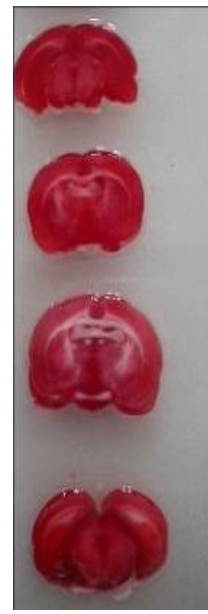

B

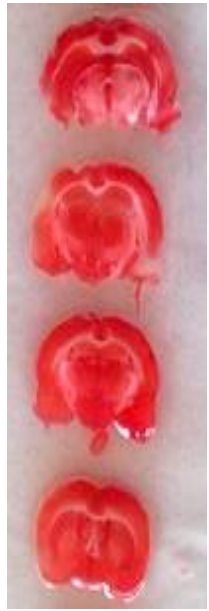

$C$

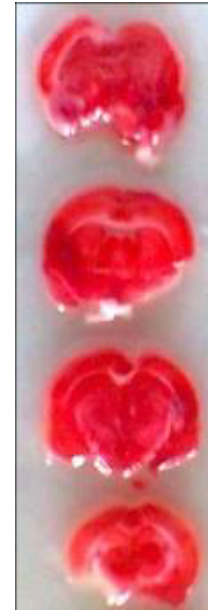

D

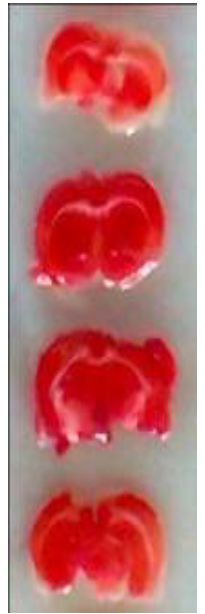

$\boldsymbol{E}$

Figure 2. Effect of hydroalcoholic extract of C. glandulosumon panel of coronel slices in rat brain subjected to BCCAO induced ischemia followed by reperfusion. The slices were stained with TTC to show the area of infarct (white color). A: Sham control, no occlusion (normal saline, $1 \mathrm{ml} / \mathrm{kg}$, p.o.), B: Reperfusion in BCCAO ischemic control (normal saline, $1 \mathrm{ml} / \mathrm{kg}$, p.o.), C: Reperfusion in BCCAO + C. glandulosum (200 mg/kg, p.o.), D: Reperfusion in BCCAO + C. glandulosum (400 mg/kg, p.o.), E: Reperfusion in BCCAO + Quercetin (10 mg/kg, p.o.).

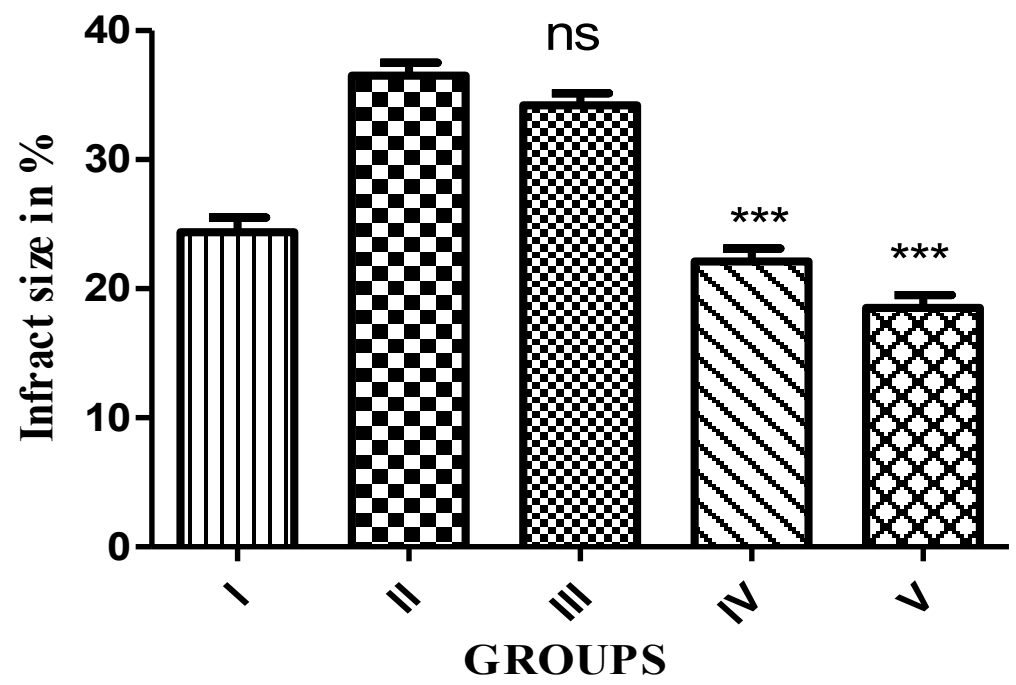

Figure 3. Effect of hydroalcoholic extract of C. glandulosum on percentage of brain infarction stained by TTC in rats subjected to BCCAO induced ischemia followed by reperfusion. I: Sham control, no occlusion (normal saline, $1 \mathrm{ml} / \mathrm{kg}$, p.o.), II: Reperfusion in BCCAO ischemic control (normal saline, $1 \mathrm{ml} / \mathrm{kg}$, p.o.), III: Reperfusion in BCCAO + C. glandulosum (200 mg/kg, p.o.), IV: Reperfusion in BCCAO + C. glandulosum (400 mg/kg, p.o.), V: Reperfusion in BCCAO + Quercetin (10 mg/kg, p.o.).

Table 4. Effect C. glandulosum on Morris water maze test in.

\begin{tabular}{|c|c|c|c|c|c|}
\hline Treatment & Dose & \multicolumn{2}{|c|}{ Escape Latencies } & \multicolumn{1}{|c|}{ Probe trial Platform } \\
\hline Groups & mg/kg,p.o. & 1 & 2 & - \\
\hline Sham & Normal saline & $5.2 \pm 0.98$ & $5.9 \pm 1.23$ & $4.3 \pm 1.67$ \\
\hline I/R & Normal saline & $4.0 \pm 1.65$ & $3.0 \pm 7.21$ & $4.6 \pm 0.83$ \\
\hline C.G & 200 & $6.09 \pm 0.98$ & $4.0 \pm 1.09$ & $5.09 \pm 0.87$ \\
\hline C.G & 400 & $7.5 \pm 1.09 *$ & $6.09 \pm 0.8$ & $5.0 \pm 0.9$ \\
\hline Quercetin & 10 & $5.87 \pm 0.23$ & $4.0 \pm 0.64$ & $5.0 \pm 0.9$ & 5.0 \\
\hline
\end{tabular}

The values are expressed as Mean \pm SD. Data was analyzed by One-Way Analysis of Variance (ANOVA) followed by Dunnett's test. $p<0.05$ as compared to I/R Vehicle control

presence of oxygen. Superoxide does not directly induce lipid peroxidation. However, the exact mechanism of CGE effect in restoration of oxidative defence is still not clear. Knowing that lipids are the most susceptible macromolecules to oxidative stress, the present results demonstrated levels of MDA in ischemia reperfusion and this finding reconfirms the observation [23]. In the present study, CGE treatment significantly improved MDA its antioxidant effect. Myeloperoxidase (MPO) is stored in azurophilic granules of leukocytes and found in neutrophils, monocytes and macrophages. In the present study, the activity of tissue MPO levels has significantly increased in I/R vehicle group as compared to sham control group. Treatment with CGE significantly reduced MDA level. Transient cerebral ischemia of 30 min followed by reperfusion for $4 \mathrm{~h}$ produced significant increase in cerebral infract size measured by volume and weight method. 2,3,5-triphenyltetrazolium chloride is believed to be 


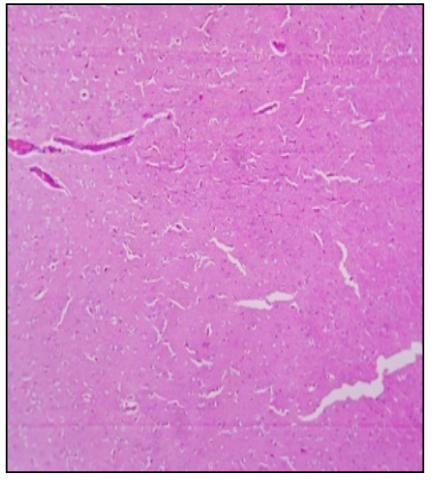

A

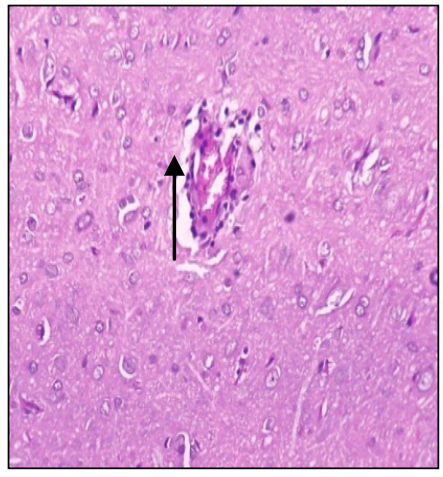

B

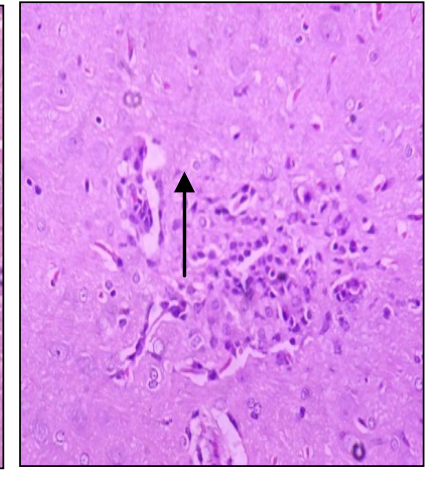

C

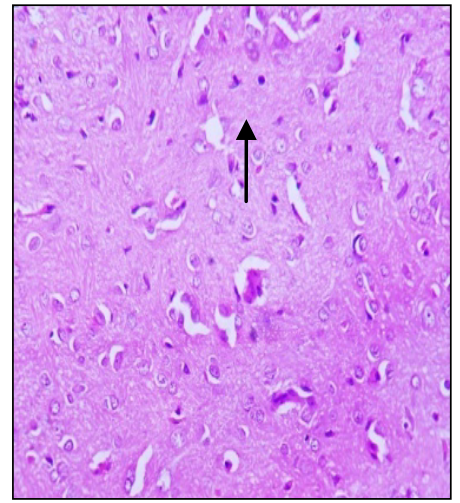

D

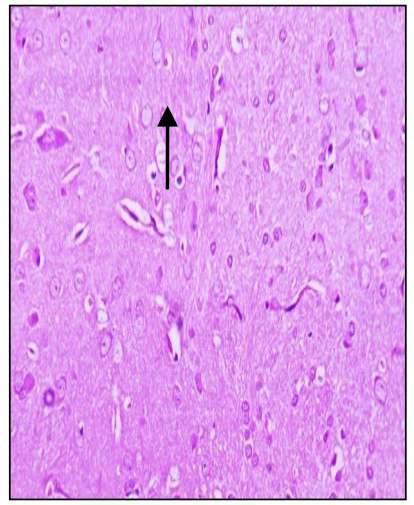

$\mathbf{E}$

Figure 4. Histopathological photographs of coronal sections of brain in rats subjected to BCCAO induced ischemia followed by reperfusion. A: Sham control, (no occlusion (normal saline, $1 \mathrm{ml} / \mathrm{kg}$, p.o.), B: Reperfusion in BCCAO ischemic control (normal saline, $1 \mathrm{ml} / \mathrm{kg}$, p.o.), C: Reperfusion in BCCAO + C. glandulosum (200 mg/kg, p.o.), D: Reperfusion in BCCAO + C. glandulosum (400 mg/kg, p.o.), E: Reperfusion in $B C C A O+$ Quercetin (10 mg/kg, p.o.).

reduced to red formazan by mitochondrial enzymes (specifically succinate dehydrogenase). On immediate TTC staining after the elective or natural death of animals, the normal tissue stains deep red and infarcted tissue with loss of mitochondrial enzyme activity does not stain and appears white [24]. Treatment of CGE shown significant decrease in infracts size compared to I/R group. Oxidative free radicals are known to contribute to ischemic brain damage. Histopathological observations made in the present study revealed that acute ischemia reperfusion did not lead to extensive ischemic neuronal changes (such as neuronal cell death). This could be correlated with earlier reports $[25,26]$. The absence of neuronal loss/death needs consideration. Glial activation, when it occurs, has consistently been shown to precede overt neuronal death $[27,28]$. Therefore, it is likely that, damage may be revealed if ischemia reperfusion is extended beyond this time point. Alternatively, the histological damage would have been apparent if more sophisticated techniques of evaluation like electron microscopy were used [29]. Even if the study indicates the cerebro-protective effect ischemia reperfusion, the results can able to correlate with the aspect of molecular mechanism of isolated compounds from the test extracts [30,31]. In conclusion, the CGE on ischemia and reperfusion induced exert a cerebro-protective effect, which may be due to its antioxidant activity $[32,33]$.

\section{Conclusion}

In conclusion, these findings suggest a potential protective role of $\mathrm{CGE}$ against global cerebral reperfusion induced brain injury. CGE reduce the neuronal loss of ischemic brain tissues. The results suggested that CGE is protective against $\mathrm{I} / \mathrm{R}$ induced oxidative stress by mechanism involving inhibition of free radical generation, reactive oxygen species scavenging modulation of intra cellular antioxidant against ischemic reperfusion induced stress.

\section{Acknowledgement}

The authors would like to express their gratitude to $\mathrm{Mr}$. Premanath Reddy, Chairman and Mrs. Shalini Reddy, Secretary, Acharya Institute, Bangalore, India, for providing the necessary facilities and support to carry out the research work.

\section{References}

1. Mori T, Asano T, Matsui T, et al. Intraluminal increase of superoxide anion following transient focal cerebral ischemia in rats. Brain Res. 1999;816:350-7.

2. Ste-Marie L, Vachon P, Vachon L, et al. Hydroxyl radical production in the cortex and striatum in a rat model of focal cerebral ischemia. Can J Neurol Sci. 2000;27:152-9.

3. Dirnagl U, Lindauer I, Tehm A, et al. Global cerebral ischemia in the rats, online monitoring of oxygen free radical production using chemiluminescence in vivo. J Cereb Blood Flow Met. 1995;15:929-34.

4. Kumura E, Yoshimine T, Iwatsuki KI, et al. Generation of nitric oxide superoxide during reperfusion after focal cerebral ischemia in rats. Am J Physiol. 1996;26:748-52. 
5. Marciniak G, Petty MA. Design and Future biological evaluation of new antioxidants for use in cerebrovascular disorders. Drugs Fut. 1996;27:1037-42.

6. Juurlink B HJ, Sweeney MI. Mechanisms that result in damage during and flowing cerebral ischaemia. Neurosci Rev Biobehav. 1997;21:121-8.

7. Harukuni I, Bhardwaj A. Mechanisms of brain injury after global cerebral ischemia. Clin Neurol. 2006;24:1-24.

8. Amanullah, Nazir S, Rehman SR. Frequency of cerebral infarction and haemorrhage in the patients of stroke. J Ayub Med Coll Abbottabad. 2009;21:102-5.

9. Jadeja RN, Thounaojam MC, Singh TB, et al. Traditional uses, phytochemistry and pharmacology of Clerodendron glandulosum Coleb-a review. Asian Pac J Trop Med. 2012;5:1-6.

10. Pandaya NB, Prakash T, Dupadakalli K, et al. Antitumor and antioxidant status of Terminalia catappa against Ehrlich ascites carcinoma in Swiss albino mice. Indian $\mathrm{J}$ Pharmacol. 2013;45:464-9.

11. Bederson JB, Pitts LH, Tsuji M, et al. Rat middle cerebral artery occlusion: Evaluation of the model and development of a neurologic examination. Stroke. 1986;17:472-6.

12. Purushottam B, Rakhunde, Saher S, et al. Neuroprotective effect of Feronialimonia on ischemia reperfusion induced brain injury in rats. Indian J Pharmacol. 2014;46(6):617-21.

13. Lister RG. Ethologically based animal models of anxiety disorders. Pharmacol Ther. 1990;46:321-40.

14. Pellow S, Chopin P, File SE, et al. Validation of open and closed arm entries in an elevated plus maze as a measure of anxiety disorders. Pharmacol Ther. 1990;46:321-40.

15. Morris R. Development of water maze procedure for studying spatial learning in the rat. J Neurosci Methods. 1984;20:185-9.

16. Dashputre NL, Wade NS. Evaluation of antiulcer activity of methanolic extract of Abutilon indicum Linn. Leaves in experimental rats. IJPSDR. 2016;6:2775-80.

17. Tiwari M, Dwived UN, Kakkar P. Suppression of oxidative stress and pro-inflammatory mediators by cymbopogon citrates D. Stapf extract in lipopolysaccharide stimulated murine alveolar macrophages. Food Chem Toxicol. 2010;48:2913-8.

18. Watanabe Y, Takagi H, Shin-ichiro A, et al. Prediction of cerebral infarct sizes by cerebral blood flow Spect performed in the early acute stage. Ann Nucl Med. 1999;90:205-10.

19. Vekaria RH, Patel MN, Bhalodiya PN, et al. Evaluation of neuroprotective effect of Coriandrum sativum Linn. against ischemic-reperfusion insult in brain. Ind J Pharmacol 2. 2012;186-193.

20. Alonso de Lecinana M, Diez-Tejedor E, Cearcellar F, et al. Cerebral ischemia: From animal studies to clinical practice. Cerebrovasc Dis. 2001;11:20-30.

21. Neumar RW. Molecular mechanism of ischaemic neuronal injury. Ann Emerg Med. 2000;36:483-506.
22. Jenkins LW, Povlishock JT, Lewelt W, et al. The role of post ischemic recirculation in the development of ischemic neuronal injury following complete cerebral ischemia. Acta Neuropathol. 1981;5:205.

23. Cao W, Carney JM, Duchon A, et al. Oxygen free radical involvement in ischemia and reperfusion injury to brain. Neurosci Lett. 1988;26:233-8.

24. Piantadosi CA, Zhang J. Mitochondrial generation of reactive oxygen species after brain ischemia in the rat. Stroke. 1996;27:327-31.

25. McCord JM, Fridovich I. Superoxide dismutase. An enzymic function for erythrocuprein (hemocuprein), J Biol Chem. 1969;25:6049-55.

26. Mukherjee PK, Ahamed KF, Kumar V, et al. Protective effect of biflavones from Araucaria bidwillii Hook in rat cerebral ischemia/reperfusion induced oxidative stress. Behav Brain Res. 2007;178:221-8.

27. Bromont $\mathrm{C}$, Marie $\mathrm{C}$, Bralet J. Increased lipid peroxidation in vulnerable brain regions after transient forebrain ischemia in rats, Stroke. 1989;20:918-24.

28. Plaschke K, Grant M, Weig MA. Neuromodulatory effect of propentofylline on rat brain under acute and long term hypoperfusion. Br J Pharmacol. 2001;133:107-16.

29. Yanpallewar SU, Hota D, Rai S, et al. Nimodipine attenuates biochemical, behavioural and histopathological alterations induced by acute transient and long-term bilateral common carotid occlusion in rats. Pharmacol Res. 2004;49:143-50.

30. Gao HM, Jiang J, Wilson B, et al. Microglia activation mediated delayed and progressive degeneration of rat nigral dopaminergic neurons: Relevance to Parkinson's disease. J Neurochem. 2002;81:1285-97.

31. Jorgensen MB, Finsen BR, Jensen MB, et al. Microglial and astroglial reaction to ischemic and Kainic acid-induced lesions of the adult rat hippocampus. Exp Neurol. 1993;120:70-88.

32. Sarti C, Pantoni L, Bartolini L, et al. Persistent impairment of gait performances and working memory after bilateral common carotid artery occlusion in the adult Wistar rat. Behav Brain Res. 2002;136:13-20.

33. Lipton P. Ischemic cell death in brain neurons. Physiol Rev. 1999;79:1431-568.

\section{*Correspondence to:}

\section{Prakash T}

Department of Pharmacology

Acharya B.M. Reddy College of Pharmacy

Bangalore-560 107

Karnataka

India

Tel: +9108028396011

E-mail: prakasht@acharya.ac.in 